\title{
Morfología causativa en el input en toba/qom (Guaycurú): Reflexiones para la adquisición de los verbos
}

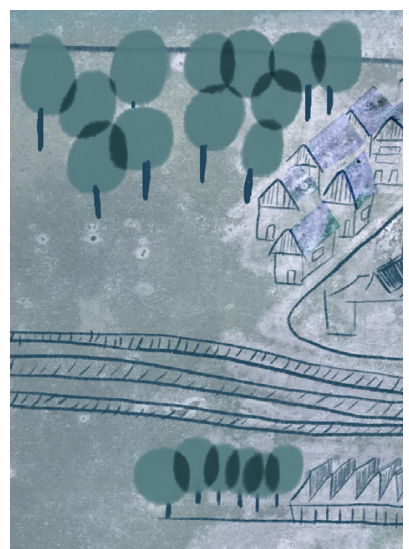

Cynthia Pamela Audisio

Consejo Nacional de Investigaciones Científicas y Técnicas, Argentina cpaudisio@gmail.com

\author{
Paola Cúneo \\ Consejo Nacional de Investigaciones Científicas y Técnicas, Argentina \\ Universidad de Buenos Aires, Argentina \\ pcuneo@gmail.com
}

\author{
Gladys Liliana Ojea \\ Consejo Nacional de Investigaciones Científicas y Técnicas, Argentina \\ gladys.ojea@gmail.com \\ Celia Renata Rosemberg \\ Consejo Nacional de Investigaciones Científicas y Técnicas, Argentina \\ Universidad de Buenos Aires, Argentina \\ celiarosemberg@gmail.com
}

\section{Resumen}

A menudo se ha llamado la atención sobre la complejidad que entraña la tarea de aprender el significado de los verbos. Investigaciones previas han estudiado la información que emplean las/os niñas/os para determinar el significado verbal. La disponibilidad de distintos tipos de información lingüística está sujeta a las características tipológicas de su lengua, pero también a su frecuencia en el input espontáneo. El toba/qom (guaycurú) exhibe estrategias de aumento o reducción de la valencia verbal que indican si el evento expresado por el verbo es causativo. En este trabajo se analizaron algunas de estas operaciones causativas y antipasivas en el input en toba/ qom a tres niños y una niña $(M=1 ; 9)$ de Chaco (Argentina). Se proporcionaron ejemplos de un corpus de habla espontánea (Rosemberg et al., 2015-2016). Asimismo, se estudiaron la frecuencia de estos mecanismos en el input. Los ejemplos mostraron que estos mecanismos constituyen evidencia útil para interpretar la semántica verbal. Además, ocurren con una diversidad de raíces verbales y en el input de todas/os las/os niñas/

Palabras clave

valencia verbal adquisición toba/qom input bootstrapping sintáctico 
os. Sin embargo, la frecuencia de los sufijos analizados en el input es baja (menor al 5\%), especialmente en el habla dirigida al/a niño/a.

\title{
Causative morphology in Toba/Qom (Guaycuruan) input: Remarks on verb acquisition
}

\begin{abstract}
Attention has often been given to the complexity entailed by the task of learning verbs. Previous research has studied the information children use to infer verb meaning. The availability of different types of linguistic information is subject to the typological characteristics of their language but also to their frequency in the input. Toba/qom (Guaycuruan) presents strategies to increase or reduce verb valency that indicate whether the event expressed by the verb is causative. In this study we have analysed some causative and antipassive operations in the input in toba/qom to three male children and one female child $(M=1 ; 9)$ from Chaco (Argentina). Examples from a corpus of spontaneous speech were provided (Rosemberg et al., 2015-2016). In addition, we have studied the frequency of these mechanisms in the input. The examples showed that these mechanisms provide useful evidence to interpret verb semantics. Moreover, they occur with a diversity of verb roots and in the input to all of the children. However, the frequency of the analysed suffixes in the input is low (less than $5 \%$ ), specially in child-directed speech.
\end{abstract}

\section{Morfologia causativa no input em toba/qom (Guaikurú): Observações sobre a aquisição de verbos}

\section{Resumo}

Atenção tem sido dada frequentemente à complexidade implicada pela tarefa de aprender verbos. Pesquisas anteriores estudaram as informações que as crianças usam para inferir o significado dos verbos. A disponibilidade de diferentes tipos de informações linguísticas está sujeita às características tipológicas da língua deles, mas também à sua frequência no input. A língua toba/qom (Guaycuruan) apresenta estratégias para aumentar ou reduzir a valência do verbo que indica se o evento expresso pelo verbo é causativo. Neste estudo, analisamos algumas operações causativas e antipassivas no input em toba/qom para três crianças do sexo masculino e uma do sexo feminino $(\mathrm{M}=1 ; 9)$ de Chaco (Argentina). Exemplos de um corpus de fala espontânea foram fornecidos (Rosemberg et al. 2015-2016). Além disso, estudamos a frequência desses mecanismos no input. Os exemplos mostraram que esses mecanismos fornecem evidências úteis para interpretar a semântica dos verbos. Eles acontecem com uma diversidade de raízes verbais e no input de todas as crianças. No entanto, a frequência dos sufixos analisados no input é baixa (menos de 5\%), principalmente na fala dirigida a crianças.

\section{Introducción}

El significado de los verbos está en parte determinado por la estructura de participantes seleccionada. La mayoría de las lenguas presentan procesos

\section{Keywords \\ verbs valency acquisition toba/qom input}

Palavras-chave

verbos valência aquisição toba/qom input 
de derivación verbal que aumentan, disminuyen o reordenan los participantes del evento expresado por el verbo. El toba/qom exhibe estrategias morfosintácticas causativas y antipasivas. Por ejemplo, construcciones causativas analíticas y morfológicas, las últimas por medio de la alternancia de índices pronominales y el uso de morfemas especializados y aplicativos. Estas estrategias han sido descritas previamente por Buckwalter (1980), Censabella (2006, 2008), González y Carpio (2017), Messineo (2003), Zurlo (2016), entre otros, también en lenguas genéticamente relacionadas como el mocoví (Carrió 2015).

La bibliografía sobre la adquisición de los verbos ha estudiado la información que emplean los/as niños/as para determinar el significado verbal. Si bien algunas investigaciones proponen que atienden principalmente a información sintáctica, otros estudios realizados con niños/as que aprenden lenguas con morfología abundante observaron que la marcación morfológica también interviene en la interpretación de la semántica verbal. De esta manera, resulta importante considerar las características tipológicas de una lengua para reflexionar acerca de su adquisición. Sin embargo, también es necesario estudiar los fenómenos gramaticales en el input espontáneo que el/la niño/a oye (Hoff-Ginsberg 1986). Debido a esto, este trabajo busca, por un lado, analizar algunas estrategias morfosintácticas que señalan cambios en la estructura de participantes del verbo en el input a niños/as qom y, por otro, reflexionar acerca de las implicaciones que tiene la presencia de este tipo de operaciones morfológicas para la adquisición de los verbos.

En §1.1 se introducen antecedentes sobre la adquisición de la semántica de los verbos, seguidos de una presentación de los aportes clásicos sobre los procesos de aumento y reducción de la valencia verbal que se utilizará en el análisis (Comrie 1976, 1981, Dixon y Aikhenvald 2000, Shibatani y Pardeshi 2002, Song 2001) en §1.2. En §1.3 se introducen las características tipológicas de la lengua toba/qom. En §2 se describe el corpus estudiado y los procedimientos de análisis. §3 presenta el análisis de algunas operaciones causativas y una operación antipasiva del toba/qom, ponderando la clase sintáctica y tipo eventual de los predicados sobre los que aplica, el tipo de causalidad involucrada y, principalmente, los efectos sobre la transitividad del enunciado y la distribución de funciones de los participantes del evento. En §3.7 se informa la frecuencia y productividad de las estrategias estudiadas en el input. Para finalizar, en $§ 4$ se concluye acerca del impacto de las operaciones revisadas en la adquisición verbal, a la luz de la evidencia proporcionada por el corpus analizado.

\subsection{La adquisición del significado de los verbos}

Investigaciones sobre la adquisición del lenguaje han llamado la atención acerca de la complejidad que entraña la tarea de aprender el significado de los verbos (Gentner 1978). Para aprender un verbo nuevo, el/la niño/a debe identificar cuántas entidades están involucradas en el evento y cómo se relacionan. Las propiedades tipológicas de las lenguas condicionan qué tipo de información se encuentra disponible para que los/as niños/as puedan determinar el significado de los verbos: léxica, sintáctica y/o morfológica. Las lenguas sin morfología abundante, como el inglés, cuentan con dispositivos sintácticos para señalar la valencia del verbo, principalmente la cantidad de argumentos expresados como elementos independientes y el orden de constituyentes. En cambio, en lenguas con morfología abundante, la valencia es indicada principalmente mediante marcas morfológicas, como 
los afijos de transitividad, causatividad o caso. Por ejemplo, en japonés los sufijos de caso nominativo y acusativo que prototípicamente ocurren en las oraciones transitivas señalan las funciones gramaticales de $\mathrm{S}_{\mathrm{y} \mathrm{O}} \mathrm{O}^{1}$. En dichas lenguas, la cantidad de frases nominales no favorece la determinación de la valencia del verbo, ya que existe la posibilidad de elidir argumentos nucleares ( $\mathrm{S}, \mathrm{A}$ y O). Las estrategias de aumento y reducción de la valencia verbal ejemplificadas en $\$ 3$ constituyen dispositivos morfológicos disponibles en toba/qom. Por ejemplo, la presencia del sufijo -agat sugiere que el verbo expresa un evento causativo en el que intervienen dos participantes: un agente que instiga la acción y un paciente que resulta afectado.

Un conjunto de estudios enmarcados en la teoría del bootstrapping sintáctico han proporcionado evidencia de que los/as niños/as emplean información sintáctica (el número y posición de las frases nominales en la oración) para acotar los significados posibles de los verbos que oyen (Fisher 1996, Gleitman 1990, entre otros). Sobre la base de la correspondencia sistemática entre el significado del verbo y las estructuras o marcos sintácticos en los que puede ocurrir, los/as niños/as infieren que los verbos en distintas estructuras sintácticas tienen diferentes significados. Por ejemplo, los verbos causativos típicamente ocurren en marcos transitivos y los verbos no causativos típicamente ocurren en marcos intransitivos. Aplicando un mecanismo de emparejamiento entre la sintaxis y la semántica, la presencia de dos frases nominales sugiere la interacción causal entre dos participantes, mientras que una única frase nominal sugiere la acción no causal de un único participante (Fisher 1996; Yuan, Fisher, y Snedeker 2012).

Tales estudios se han realizado, sobre todo, en poblaciones de niños/as occidentales de clase media que se encuentran aprendiendo inglés. Como se expuso, en esta lengua los argumentos del verbo deben ser expresados en la oración por medio de frases nominales, determinando que los marcos sintácticos (i.e., el número y la posición de las frases nominales de la oración) informen sobre la valencia del verbo. Sin embargo, ciertos estudios muestran que la cantidad de frases nominales en la oración representa la información más atendida por los/as niños/as, aún en aquellos/as que aprenden lenguas morfológicamente ricas, como el chino mandarín (Lee y Naigles 2008), el kannada (Lidz, Gleitman y Gleitman 2003) y el turco (Göksun, Küntay y Naigles 2008). Mediante estudios experimentales, se ha concluido que la aplicación de este mecanismo es universal y muy temprana —desde los 19 meses, según Yuan et al. (2012)_-de manera tal que precede la detección de otras pistas de transitividad tipológicamente específicas para cada lengua, por ejemplo, la presencia de morfemas causativizadores. En otras palabras, los/as niños/as comienzan aplicando un mecanismo de emparejamiento entre la sintaxis y la semántica de una oración que toma en cuenta la cantidad de frases nominales, independientemente de que su lengua proporcione dispositivos más consistentes para indicar el significado verbal.

Los hallazgos de estos estudios difieren de otros que muestran que los/ as niños/as atienden a los dispositivos más consistentes en su lengua, los cuales no necesariamente son sintácticos (MacWhinney 1987). En efecto, los/as niños/as que adquieren lenguas con morfología abundante emplean las marcas morfológicas para procesar las relaciones gramaticales de una oración. Ammon y Slobin (1979) y Slobin (1982) encontraron que niños/as $(2 ; 0-4 ; 4)$ que adquieren lenguas con dispositivos morfológicos para expresar el significado causativo de los verbos, como el serbocroata y el turco,
1. Se utilizan las siguientes iniciales para referir a los argumentos nucleares: $\mathrm{S}=$ argumento único de la cláusula intransitiva; $\mathrm{A}=$ argumento más parecido al agente de la cláusula transitiva; $\mathrm{O}=$ argumento más parecido al paciente/objeto de la cláusula transitiva. 
desarrollan estrategias de procesamiento oracional más rápidamente que los/as niños/as que adquieren lenguas con dispositivos sintácticos para indicar causalidad, como el inglés y el italiano. Las marcas morfológicas que expresan el significado causal del verbo, como los sufijos de caso del turco, propician la comprensión temprana de las relaciones gramaticales oracionales porque son interpretadas localmente. Por el contrario, los dispositivos sintácticos, como el orden de palabras del inglés, requieren la integración de información que se encuentra distribuida en la oración (Slobin 1982).

Incluso algunos estudios realizados desde el marco del bootstrapping sintáctico también presentan evidencia en este sentido. Matsuo et al. (2012) encontraron que la presencia de marcadores de caso nominativo y acusativo en la oración es necesaria para que niños/as japoneses/as de 2;4 años interpreten el verbo como causativo. Esta interpretación no es suscitada si únicamente se emplean recursos sintácticos, esto es, la presencia de dos argumentos verbales. Tales hallazgos son esperables dadas las características tipológicas del japonés. En esta lengua, el sujeto y el objeto directo pueden omitirse y son pre-verbales, determinando que la cantidad y la posición de las frases nominales no ayuden a desentrañar el significado de los verbos. Más aún, mientras que estos recursos sintácticos no generan por sí solos la interpretación causativa del verbo por parte de niños/as que aprenden japonés, Suzuki y Kobayashi (2016) mostraron que la presencia de marcas de caso acusativo es suficiente para suscitarla.

Si bien las propiedades tipológicas de las lenguas contribuyen a que los/as niños/as privilegien la utilización de un dispositivo gramatical por encima de otros para interpretar los verbos, las particularidades del input lingüístico de esas lenguas influyen en la frecuencia y consistencia con que esas propiedades se manifiestan. Los casos del japonés y el coreano son ilustrativos en este punto. Estas lenguas presentan muchas similitudes entre ellas: son aglutinantes, pro-drop, tienen marcación morfológica de caso, etc. No obstante, en la producción inicial de los/as niños/as japoneses/ as predominan los verbos intransitivos (Tsujimura 2006), y en la de los/ as niños/as coreanos/as predominan los verbos transitivos (Choi 1999). Fukuda y Choi (2009) hallaron que las diferencias en el input recibido por los/as niños/as japoneses/as y coreanos/as $(1 ; 11-2 ; 6)$ explican su producción temprana. El input que las/os cuidadoras/es coreana/os dirigen a las niñas de hasta 2 años durante interacciones espontáneas incluye una cantidad significativamente mayor de verbos transitivos y una cantidad significativamente menor de verbos intransitivos que el input de las/os cuidadoras/ es japonesa/es. Asimismo, fue encontrada una correlación significativa en el uso de predicados transitivos e intransitivos (en tokens) por parte de los/ as niños/as y sus cuidadores/as.

En conformidad con estos planteos, el Modelo de Competición (MacWhinney 1987) postula que las propiedades distribucionales del input en una determinada lengua determinan la adquisición y el procesamiento del lenguaje. Por ejemplo, las características formales sintácticas y/o morfológicas de mayor consistencia y disponibilidad guían la comprensión y la adquisición temprana del lenguaje en mayor medida. Por ejemplo, Rispoli (1995) sostiene que los/as niños/as japoneses/as de 2 años no pueden emplear las marcas de caso acusativo para inferir el significado de verbos nuevos porque sólo un $7 \%$ de los enunciados espontáneos de los/as cuidadores/as japoneses/as contienen estas marcas. Matsuo et al. (2012) encuentran evidencia similar. En cambio, Morikawa (1989) y otros/as cuestionan el cálculo de Rispoli 
(1995) y sostienen que la presencia de marcas de caso en el input no es deficiente. En consecuencia, es de suma importancia analizar la información que el input en distintas lenguas proporciona al/a niño/a para descubrir el significado de los verbos.

Las investigaciones mencionadas sostienen que la información gramatical de las oraciones que el/la niño/a escucha, tanto en lo que respecta a sus características tipológicas como a su distribución en el input, guía sus representaciones semánticas de los verbos. En cambio, otra línea de estudios conocida como bootstrapping semántico postula que son las representaciones semánticas las que guían el descubrimiento de las reglas gramaticales de una lengua (Pinker 1984). Así, el/la niño/a se concentra en la semántica del evento expresado por el verbo para descubrir cuáles son los argumentos involucrados en el mismo. Por ejemplo, el significado de un verbo como romper necesariamente involucra un participante que ejecuta la acción y otro que sufre la rotura. Por medio de reglas de enlace (linking rules) innatas que vinculan los roles temáticos asignados por un verbo y las funciones sintácticas en la oración, determina que el agente se realiza como sujeto oracional y, el paciente, como objeto. En línea con estas propuestas, hay autoras/es que han cuestionado el impacto de la información sintáctica proporcionada por el input en el aprendizaje inicial del significado de los verbos.

Por ejemplo, a partir de un experimento con 42 niños/as hablantes de inglés (3;5), Ingham (1993) sostiene que los datos sintácticos del input tienen importancia secundaria en la adquisición de las representaciones léxicas de los verbos transitivos. En su lugar, el significado verbal es inferido a partir de los roles temáticos cognitivamente disponibles en el input situacional no-lingüístico. Por su parte, Ninio $(2015,2016)$ cuestiona que el aprendizaje verbal comience con un mecanismo de bootstrapping sintáctico, porque éste requiere que los/as niños/as escuchen los verbos en oraciones completas. En cambio, sostiene que los/as niños/as empiezan a aprender el significado de los verbos a partir de enunciados de una palabra. Éstos admiten más fácilmente ser interpretados a partir de las intenciones de los/as interlocutores/as y el contexto no-lingüístico del input. Como evidencia, la autora halló que la frecuencia de los verbos producidos por niños/as hablantes de hebreo e inglés en enunciados de una palabra guarda mayor correlación con la frecuencia de los verbos del input, frente a aquella que se encuentra en enunciados completos.

\subsection{Los procesos de aumento y disminución de valencia}

La derivación causativa afecta prototípicamente a verbos intransitivos y deriva verbos transitivos. Por medio de ella, se introduce un argumento causante A y el participante $\mathrm{S}$ de la cláusula intransitiva original se convierte en O de la cláusula transitiva en la que expresa el argumento causado. Algunas lenguas admiten procesos de causativización en verbos transitivos e incluso ditransitivos. En estos casos, diferentes posibilidades de acomodamiento para los argumentos A y O de la cláusula original permiten mantener el número máximo permitido de argumentos nucleares por cláusula. En toba/qom, como también en blackfoot, bandjalang, halkomelem, el verbo transitivo debe detransitivizarse antes de llevarse a cabo la derivación causativa (ver §3.5).

Se ha sugerido que las construcciones causativas involucran dos eventos: (i) uno causante, por el cual un participante realiza una acción que 
desencadena en un evento (ii); y (ii) uno causado, por el cual un segundo participante realiza una acción o sufre un cambio de estado o condición como resultado de la acción iniciada por el primer participante en (i). La separación temporal entre el evento causante y el evento causado determina la distinción entre causalidad directa e indirecta. Si el evento causado se produce inmediatamente luego del evento causante, entonces la causalidad expresada es directa. De no existir secuencialidad inmediata entre ambos eventos o de ocurrir otros eventos entre ellos, la causalidad expresada es indirecta (Shibatani y Pardeshi 2002).

Comrie (1981) ha sugerido que, según el tipo de causalidad expresada (directa o indirecta), los mecanismos de causativización se organizan en un continuum que va desde un polo léxico hasta un polo analítico pasando por los mecanismos morfológicos de causativización. De este modo, la distancia gramatical refleja la distancia conceptual entre el evento causante y el evento causado (Song 2001). Respecto de la causalidad morfológica, el objeto de este trabajo, el predicado de causa es expresado como un morfema derivacional y el predicado de efecto es expresado mediante el contenido léxico del verbo de base. A su vez, entre los mecanismos morfológicos de una lengua, también es posible identificar la gradación o continuum antes mencionado. Por ejemplo, un afijo corto es más compacto que otro más largo. Entre los sufijos estudiados aquí, -aqchet y -aganagan son más largos, ya que están formados por la combinación de otros sufijos (ver §3.3 y §3.5) y precisamente pueden expresar causalidad indirecta.

La derivación antipasiva afecta prototípicamente a verbos transitivos y deriva verbos intransitivos. Este tipo de derivación determina que el participante A se convierta en S mediante la democión del argumento $\mathrm{O}$ a una posición periférica. Desde el punto de vista semántico, la construcción antipasiva permite enfocar el hecho de que el participante A realiza una actividad, desestimando la identidad del participante afectado por dicha actividad. Dixon y Aikhenvald (2000) mencionan la existencia de dos tipos de construcciones antipasivas: unas que admiten la inclusión del argumento O ("antipasivas prototípicas"), y otras que no lo hacen ("antipasivas sin paciente"). Cabe señalar que las operaciones de derivación antipasiva son más comunes en lenguas con características ergativas (Dixon 2000), lo cual coincide con algunas de las características mencionadas en $\S 1.3$.

\subsection{Características tipológicas de la lengua toba/qom}

El toba o qomliaqtaqa es una lengua de la familia guaycurú ${ }^{2}$. El grupo étnico qom comprende cerca de 127.000 personas en la Argentina (INDEC 2012) y 2.057 en Paraguay (DGEEC 2015). En Argentina, la mayoría de la población qom se encuentra asentada en comunidades rurales y semi-urbanas en las provincias de Chaco, Formosa y Salta. Debido a movimientos migratorios, también existen asentamientos en grandes centros urbanos de la zona central del país como Resistencia, Rosario, Buenos Aires y La Plata (Censabella, 2000; Messineo, 2003).

La lengua toba/qom muestra tendencia a la polisíntesis y la aglutinación. No posee marcación de caso y se caracteriza por la complejidad morfológica de nombres y verbos. Los verbos pueden constituir por sí mismos una oración y, si bien no presentan flexión de tiempo o modo, incluyen sufijos que expresan distinciones aspectuales, dirección, posición, reflexividad y
2. El inventario fonológico del toba/ qom (ver Messineo 2003) abarca cuatro fonemas vocálicos /a, e, i, o/. Los fonemas consonánticos se listan a continuación con las correspondencias ortográficas utilizadas en este trabajo [entre corchetes]. Entre los labiales se incluyen el oclusivo sordo $/ \mathrm{p} /$, el nasal $/ \mathrm{m} / \mathrm{y}$ el glide sonoro $/ \mathrm{w} /$ Los fonemas alveolares abarcan el oclusivo sordo /t/ y el sonoro /d/, el fricativo sordo /s/, el nasal /n/, el tap sonoro // [r/d] y el lateral sonoro /l/. Los fonemas palatales comprenden el oclusivo sordo /t / [ch] el fricativo sordo // [sh] y el sonoro // [z], el nasal / / [ñ], el lateral sonoro // [II] y el glide sonoro/j/ [y]. Entre los velares se encuentran el oclusivo sordo /k/ y el sonoro /g/ El fonema oclusivo sordo /q/ y el sonoro / / constituyen los fonemas uvulares. Por último, el inventario fonológico del toba/qom incluye un fonema glotal oclusivo sordo / / 
reciprocidad. Las operaciones de modificación de la valencia verbal son la reflexiva, recíproca, antipasiva, impersonal y varias construcciones causativas y aplicativas.

En la variedad del área centro-norte de la provincia de Chaco, coexisten dos mecanismos para codificar los argumentos de una construcción transitiva: uno morfológico y otro sintáctico (Messineo 2003, 2016). El procedimiento morfológico opera por indexación en el verbo, la cual habilita la omisión de frases nominales en la cláusula, tanto A como O. Cuando uno de los participantes no forma parte del acto de habla, los predicados transitivos admiten sólo un índice de persona, cuya selección no depende del rol temático, sino de la posición relativa de los dos argumentos sobre la jerarquía de persona, según la cual la $1^{\underline{a}}$ y la $2^{\underline{a}}$ comparten la posición más alta, mientras que la $3^{\text {a }}$ ocupa la más baja. Si los dos participantes forman parte del acto de habla (1a, 2a), se ha aducido que ambos son admitidos como índices en el verbo transitivo en el que se expresan amalgamados.

El procedimiento sintáctico de codificación de participantes de predicados transitivos involucra un orden de constituyentes diferenciado según la posición del participante en la jerarquía de persona. A pesar de ser flexible, el orden de constituyentes no marcado en las cláusulas transitivas es AVO (y VS en las intransitivas). No obstante, el participante $\mathrm{O}$ de 1a o 2a persona se ubica en posición preverbal (AOV) y el participante $\mathrm{O}$ de 3a persona se ubica en posición posverbal (AVO).

Los verbos contienen obligatoriamente un índice de persona prefijado, a pesar de que sus argumentos se encuentren expresados como frase nominal o pronombres independientes. Estos índices se agrupan en tres paradigmas de conjugación según el grado de agentividad o afectación del participante codificado y del contenido léxico del verbo: activo, medio e inactivo. Además de indicar el actor, también señalan la direccionalidad de la acción que o bien se aleja del actor (paradigma activo), se acerca a él o bien lo involucra (paradigma medio, Buckwalter 1980, Klein 1981). Adicionalmente, la 3a persona del paradigma activo muestra una escisión vinculada con una escala de transitividad (Messineo 2003) y diferentes grados de control y afectación, constituyendo un rasgo de ergatividad (Carpio 2007, Censabella 2008). No obstante, sus formas se encuentran en gran parte lexicalizadas.

Debido a la existencia de marcas diferenciadas para los sujetos de cláusulas intransitivas, siendo aquellas del paradigma inactivo isomórficas con las marcas de objeto, Messineo (2003) identifica al toba/qom como una lengua de tipo activo/inactivo o de intransitividad escindida en que $\mathrm{A}=\mathrm{SA}$ y $\mathrm{O}=\mathrm{SO}$ (Dixon 1994). Otras autoras (Carpio 2007, Censabella 2008) enfatizan que sólo unas pocas raíces siguen el sistema activo/inactivo, por lo que en realidad son dos los paradigmas de conjugación (activo y medio).

No existe acuerdo absoluto en la bibliografía en relación con las clases sintácticas de los verbos. A diferencia de quienes dividen las raíces verbales en transitivas e intransitivas (Censabella 2006, 2008, Zurlo 2016), Cúneo y Messineo (2019) asumen que no hay una división absoluta: la transitividad depende de la configuración de los índices pronominales y de los mecanismos de aumento y reducción de la valencia verbal.

Cabe señalar que el toba/qom se diferencia de lenguas en las que, además de $\mathrm{A}$ y $\mathrm{O}$, el receptor o beneficiario tiene un estatus nuclear y no puede 
omitirse en construcciones que expresan eventos de dar, mostrar o contar. En esta lengua, no existe una clase de verbos ditransitivos. En cambio, los argumentos receptores o beneficiarios requieren la adjunción de aplicativos en el verbo para ser promovidos.

\section{Metodología}

\subsection{Corpus}

Este trabajo emplea un corpus que reúne transcripciones de interacciones con niños pequeños en el hogar (Rosemberg et al. 2015-2016) ${ }^{3}$. Las mismas fueron realizadas por Rosemberg y sus colegas en colaboración con hablantes bilingües qom-español, de acuerdo con el formato CHAT (MacWhinney 2000). El proceso de transcripción involucró la identificación de los/as hablantes como adultos/as (> 12 años) o niños/as ( $\leq 12$ años) y de los/as destinatarios/as como niños/as (el bebé con el grabador u otro/a niño/a presente de hasta 4 años), u otros/as participantes adultos/as. El proceso de transcripción incluyó al menos tres instancias de revisión. En total se analizó el input toba/qom de 4 horas de audio, correspondientes a las transcripciones de 1 hora de audio de 3 niños y 1 niña qom $(M=1 ; 9)$.

Las familias de los niños/as que fueron registrados/as viven en la zona periurbana de Pampa del Indio, en la provincia de Chaco (Argentina). Con excepción de las personas más ancianas de la comunidad, que viven alejadas del pueblo, en el medio rural, los qom de Pampa del Indio son bilingües qom-español. Por fuera del grupo indígena, el bilingüismo qom-español es excepcional. La localidad se caracteriza por una situación diglósica en la que el español es la lengua mayoritaria y dominante que se utiliza en los espacios públicos (hospitales, comercios, etc.), y el qom es la lengua minoritaria que se habla fundamentalmente en espacios privados (el contexto familiar y las actividades socioculturales en el ámbito comunitario). De este modo, tanto el qom como el español están presentes en la vida cotidiana de las familias qom que viven en Pampa del Indio ${ }^{4}$. En los contextos familiares que observamos, se presenta un uso alternado de ambas lenguas con cambio de código de tipo conversacional (Gumperz 1982), según el cual qom y español se usan en una misma interacción ${ }^{5}$.

Se incluyen asimismo en el trabajo algunas oraciones seleccionadas del Vocabulario toba de Buckwalter (1980).

\subsection{Procedimiento}

El análisis recoge algunas operaciones morfológicas de aumento y disminución de la valencia verbal en el input en toba/qom a 3 niños y 1 niña: Ab $(1 ; 2)$, Na $(2 ; 2), \operatorname{Tg}(2 ; 0)$ y Tz $(1 ; 8)$. En particular, aquellas operaciones determinadas por la adjunción de los sufijos -agan, -aganagan, -agat y -aqchet.

En un primer momento, se extrajeron del input los enunciados en toba/ qom, es decir, 1442 enunciados. A continuación, se rastrearon aquellos que incluyeran los sufijos mencionados, así como sus variantes alomórficas (por ejemplo, -ogon, -agaa, -ogooen el caso de -agan). Luego se identificaron las raíces a las que se encontraban ligados y se localizaron ocurrencias no derivadas de esas raíces en los enunciados del input. Esto permitió cotejar
3. La recolección, transcripción y codificación de hablantes y destinatarios fue llevada a cabo por Rosemberg y colegas en el marco del proyecto de investigación "Vocabulario, narración y argumentación infantil: Un estudio psicolingüístico y sociocultural", PIP 80/2015, CONICET, Argentina, 2015-2018, cuyo objetivo es estudiar el desarrollo lingüístico de niños monolingües español y bilingües español-qom en contextos de interacción espontáneos, empleando técnicas habituales del trabajo etnográfico. Los ejemplos para los que no se indica la fuente entre paréntesis han sido extraídos de emisiones de este corpus.

4. La descripción de la situación sociolingüística de la comunidad en la que se insertan los/as niños/as de este estudio ha sido tomada de Ojea (2017). En este texto, también se indaga acerca de la condición de bilingües de los niños qom nacidos y criados en esta comunidad. Remitimos al/a lector/a a este texto para obtener más información al respecto.

5. Para una descripción general del entorno lingüístico temprano de los/ as niños/as qom que viven en esta comunidad rural indígena, véase Audisio, Rosemberg, Ojea, \& Cúneo (2019), donde se analiza la presencia del español y el qom en el input y se observan fenómenos de contacto lingüístico, en particular el cambio de código y los préstamos léxicos. 
las raíces en su forma derivada y no derivada para ponderar las modificaciones en la valencia verbal y la expresión de los participantes del evento determinadas por la derivación.

Los enunciados del input seleccionados de esta manera fueron segmentados en cláusulas. En total, se analizaron 118 cláusulas de las cuales: 42 contenían verbos derivados mediante alguno de los sufijos estudiados, y 76 contenían ocurrencias no derivadas de aquellos verbos. La tabla 1 incluye información acerca del material analizado.

En el análisis, se ponderó el efecto de la derivación morfológica, se identificaron los tipos de bases verbales (en cuanto a sus valores aspectuales y transitividad) que admiten la adjunción de los sufijos estudiados y se determinó el tipo de causalidad expresada a partir de la evaluación de traducciones hechas por hablantes nativos. Además, se llevó a cabo una descripción cuantitativa de los sufijos estudiados en el input.

\begin{tabular}{|c|c|c|c|c|c|}
\hline Niño & Edad & Cláusulas & Raíces & & Sufijos \\
\hline $\mathrm{Ab}$ & $1 ; 2$ & 21 & $\begin{array}{l}\text {-achel ‘bañar’ (1), } \\
\text {-an ‘dar’ (1), } \\
\text { - awik 'arder’ (6), } \\
\text {-er ‘escribir’ (1), } \\
\text {-qat ‘sacar’ (6), }\end{array}$ & $\begin{array}{l}\text {-qin ‘saludar' (1), } \\
\text {-ra 'mover' (1), } \\
\text {-tet 'coser' (1), } \\
\text {-?aqt 'hablar' (1) } \\
\text {-?aGGai'escuchar' (2) }\end{array}$ & $\begin{array}{l}\text { - } a_{G} \text { an CAU (2), } \\
\text { - a } a_{G} \text { an DTR (3), } \\
\text { - a } a \text { at CAU (6) }\end{array}$ \\
\hline $\mathrm{Na}$ & $2 ; 2$ & 55 & $\begin{array}{l}\text {-achel 'bañar' (1), } \\
\text {-an 'dar' (2), } \\
\text {-er 'escribir' (1), } \\
\text {-yo 'lavar' (2), } \\
\text {-malla ‘hablar' (2), } \\
\text { - qat 'sacar' (13), } \\
\text {-shepa }{ }_{G} \text { an 'ensuciar'(4), }\end{array}$ & 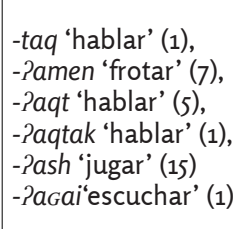 & $\begin{array}{l}\text { - a } a_{G} \text { an CAU (6), } \\
\text { - aGan DTR (5), } \\
\text {-aqchet CAU (3), } \\
\text { - a }{ }_{G} \text { ana }{ }_{G} a n \text { CAU (1) }\end{array}$ \\
\hline $\operatorname{Tg}$ & $2 ; 0$ & 19 & $\begin{array}{l}\text {-achel ‘bañar’ (1), } \\
\text {-alawat ‘matar’ (1), } \\
\text { - ata? ‘curar’ (1), } \\
\text { - awot ‘asar’ (1), } \\
\text {-yo 'lavar’ (5), }\end{array}$ & $\begin{array}{l}\text {-qat ‘sacar' (5), } \\
\text {-qowin 'cazar' (2), } \\
\text {-?aqt ‘hablar' (1), } \\
\text {-?aGai'escuchar’ (1), } \\
\text {-?on 'cantar' (1) }\end{array}$ & -aGan DTR (11) \\
\hline $\mathrm{Tz}$ & $1 ; 8$ & 23 & $\begin{array}{l}\text {-an ‘dar’ (2), } \\
\text {-awik ‘arder’ (3), } \\
\text {-yo ‘lavar’ (2), }\end{array}$ & $\begin{array}{l}\text {-taq ‘hablar’(4), } \\
\text {-?ash ‘jugar’ (10), } \\
\text {-?er 'arder’ (2) }\end{array}$ & $\begin{array}{l}\text { - } a_{G} \text { an DTR (1), } \\
\text { - } a_{G} a t \text { CAU (4) }\end{array}$ \\
\hline
\end{tabular}

Tabla 1. Edad de los niños y la niña cuyo entorno lingüístico registra el corpus analizado, cantidad de cláusulas, raíces y sufijos analizados por niño/a.

\section{Análisis}

\subsection{El sufijo causativizador - $a_{G} a n$}

En el input, el morfema causativizador-agan se adjunta a las raíces -ra 'mover', -achel 'bañar', -malla 'hablar', -?ash 'jugar' y -taq 'hablar'6 . La bibliografía coincide en señalar la función causativa de este sufijo, cuya adjunción determina el aumento de la valencia del verbo de base intransitivo y deriva verbos transitivos (Buckwalter 1980, Censabella 2006, 2008). Carrió (2015) también detecta este funcionamiento en mocoví, una lengua emparentada de la familia Guaycurú. En el ejemplo (1) del input, se ilustra esta función. La oración $(1 \mathrm{a})^{7}$ presenta un evento con un único participante $\mathrm{S}_{\mathrm{A}}$ que realiza una acción de cuidado corporal sobre sí mismo. En cambio, en (1b), la adjunción del sufijo causativizador-agan determina la transformación del participante $\mathrm{S}_{\mathrm{A}}$ de la cláusula intransitiva en $\mathrm{O}$, y la inclusión de un segundo participante A.
6. Las siguientes abreviaturas gramaticales se utilizan para las glosas: A (participante agente/activo); aus (ausente); CAU (causativo); D (clasificador deíctico); DEM (demostrativo); DES (desiderativo); DIR (direccional); dist (distante); DUR (aspecto durativo); DTR (detransitivizador); EXNEG (existencial negativo); FEM (género femenino); I (participante inactivo); IMP (impersonal); INTERJ (interjección); INTERR (interrogativo); LOC (locativo); M (participante medio); MASC (género masculino); NEG (negativo); NMZ (nominalizador); PC (paucal); PL (plural); POS (poseedor); PROG (aspecto progresivo); PRON (pronombre personal); prox (próximo); SG (singular); trid (tridimensional); vert (vertical); 1 (primera persona); 2 (segunda persona); 3 (tercera persona).

7. Los ejemplos para los que no se indica la fuente han sido extraídos de un corpus de habla espontánea (ver nota 3). Por esta razón, muchos de ellos tienen características típicas del habla situada, como la ausencia de frases nominales que identifican elementos salientes en el contexto. Por ejemplo, la cláusula (1b) ocurre sin un objeto independiente a pesar de ser transitiva. Al respecto, es importante recordar también (ver §1.3) que en toba/qom los predicados transitivos admiten solo un índice de persona cuya selección depende de la jerarquía de persona $(1 / 2>3)$. En el ejemplo (1b) (también en (3c)), el argumento más alto en la jerarquía ( $2^{\underline{a}}$ persona) es el marcado. El argumento más bajo en la jerarquía ( $3^{\mathrm{a}}$ persona) no se marca en el verbo y debe expresarse como frase nominal independiente. Sin embargo, y por las razones aducidas anteriormente y que se vinculan al carácter espontáneo de estos enunciados, este argumento falta. Para facilitar la comprensión, hemos introducido en la traducción los constituyentes elididos entre corchetes. 
(1)

a.

saGanaGanachelñi?iñi

$\begin{array}{lll}\text { saGanaGa }_{\text {todáa.no }} & \text { n-achel } & \text { ñi?iñi } \\ \text { todavín. } & \text { 3SG.M-bañar } & \text { DEM.MASC.trid }\end{array}$

‘Todavía no se bañó él’.

b.

$m a(m a ́)$, ?anachela $a_{G} a n$

ma(má) Pan-achel-agan

ma(ma) 2SG.M-bañar-CAU

'Mamá, [lo] vas a bañar'.

En relación con los eventos expresados por el verbo de base, predominan las actividades - por ejemplo, 'moverse', 'hablar', 'conversar', 'jugar' aunque también hay realizaciones - como 'bañarse'- Tal como se indica en la bibliografía, la adjunción de -agan causativo conlleva un cambio en el marcador de 3a persona, de la forma intransitiva $r$ - [d-] a la forma transitiva $i-[y-]$, que codifica un participante agentivo. Todos los ejemplos del input en 3a persona singular activa ocurren con la marca transitiva $i-[y-]$.

En el input, los verbos de base que reciben el sufijo -agan causativo suelen seleccionar el índice $r$ - [ $d$-] cuando se encuentran conjugados en 3a persona activa. Este índice puede codificar un participante, ya sea con menor volición, menor control y mayor afectación (SO), o bien con mayor volición, mayor control y menor afectación (SA). En relación con el mocoví, Carrió (2015) señala que, si bien no es del todo claro el criterio de selección de los verbos de base, el sufijo parece estar restringido a bases verbales inergativas. Nuestros ejemplos confirman esta observación para el toba / qom, dado que los verbos de base en general son inergativos. Solo una de las raíces del input, -ra 'mover' puede ocurrir también en cláusulas intransitivas con un SO (2a). La derivación con -agan(2b) determina la inclusión de un participante causante A.

(2)

a.

da dedatakañii?aite, i?aGata?a da ñiqi?ik

$\begin{array}{llll}\text { da } & \text { de-da-tak } & \text { añi } & \text { i-Pai-te, } \\ \text { D.vert } & \text { 3SG.A-mover-PROG } & \text { FEM-D.trid } & \text { 1SG.POS-ojo-PC } \\ \text { i-PaGata-?a } & \varnothing \text {-da } & \text { ni-qi?ik } & \\ \text { 3SG.A-predecir-DIR } & \text { MASC-D.vert } & \text { 1SG.POS-dolor } & \end{array}$

'Cuando mi ojo se mueve involuntariamente, anuncia mi sufrimiento venidero'.

Buckwalter (1980)

b.

qaikakaida $_{G} a n a i ?$

qaika $\quad$-ka i-da-Gana-i?

EXNEG MASC-D.aus 3SG.A-mover-CAU-LOC

'Nadie lo mueve, queda para siempre'. Buckwalter (1980)

Además de permitir la inclusión de un participante causante a una cláusula intransitiva con un único argumento (SA o SO), la adjunción de -agan parece posibilitar otra transformación. Con una de las raíces del input (-?ash 'jugar'), se observó que la derivación determina la transformación del participante agentivo único (SA) en A, y la inclusión de un participante afectado $(\mathrm{O})$-en este caso, el juguete o juego-. 
Como sugieren los ejemplos (1b) y (2b), la causalidad expresada a partir de la adjunción de este sufijo es directa e intencional (Censabella 2006, 2008). Carrió (2015) observa para el mocoví que la adjunción de -agan habilita una lectura factitiva ("hacer hacer"), expresando así causalidad indirecta, con dos participantes agentivos y dos sub-eventos que suceden en dos momentos diferentes y, potencialmente, en dos espacios diferentes. Uno de los ejemplos del input presentado, como (3c), parece sugerir que la lectura factitiva también es posible en toba/qom luego de la inclusión de -agan causativo. Los ejemplos (3a-b) ilustran el uso de la raíz -malla 'hablar' sin el morfema causativizador.

(3)

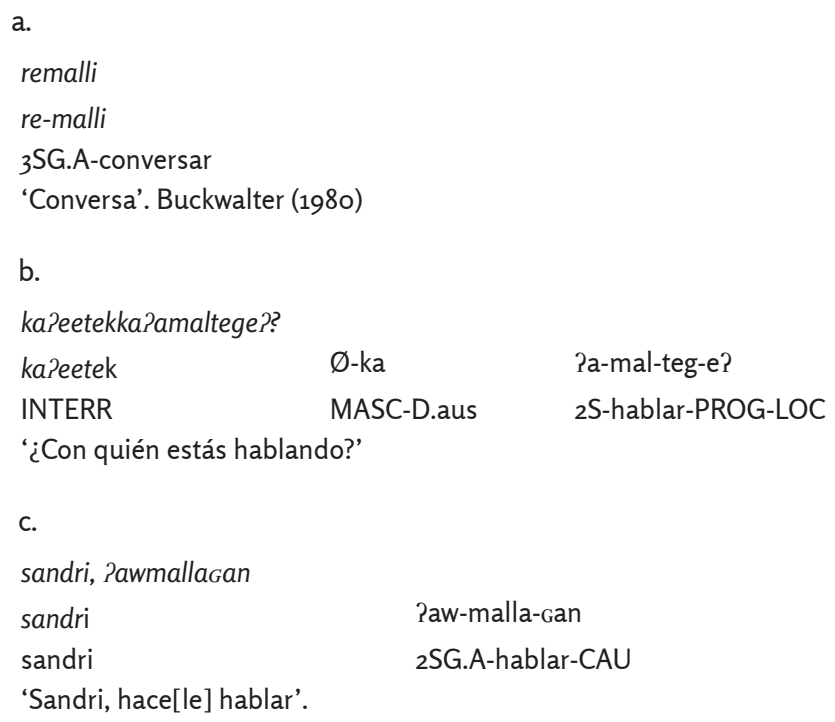

Como señala Censabella (2006, 2008), la derivación causativa con -aGan se encuentra en muchos casos lexicalizada y su productividad es baja. En (4), por medio de la adjunción de -agan, el verbo -taq 'hablar' adquiere un significado idiosincrásico ('leer') no completamente esperable como efecto semántico regular de la causativización del verbo de base.

(4)

a.

\begin{tabular}{|c|c|c|c|}
\hline se-taq-tak & ka(illa)ye & $\varnothing$-wota-iqe & n-ie-wek \\
\hline 1SG.A-hablar-PROG & en ese momento & 3SG.A-querer-DES & 3SG.M-salir?-DIR \\
\hline$a$-ñe & i-we & & \\
\hline FEM-D.trid & 1SG.POS-diente & & \\
\hline \multicolumn{4}{|c|}{ ‘Estoy hablando y quiere salirse mi diente’. } \\
\hline \multicolumn{4}{|l|}{ b. } \\
\hline \multicolumn{4}{|l|}{ itaGaya ${ }_{G}$ anra abel } \\
\hline i-taGay- $a_{G} a n$ & $\varnothing$-ra & abel & \\
\hline 3SG.A-leer-CAU & MASC-D.vert & Abel & \\
\hline
\end{tabular}

\subsection{El sufijo causativizador-aGat}

Este sufijo permite derivar verbos transitivos a partir de bases intransitivas, a la vez que aumenta su valencia (Censabella 2006, 2008, González y 
Carpio 2017 —sobre la variedad hablada en Formosa-, Carrió 2015 —sobre el mocoví-). Así, un verbo que expresa un evento que involucra a un único participante pacientivo pasa a expresar la acción de un participante agente sobre un paciente. Por ejemplo, mientras que en (5a) el verbo ?eroigi selecciona un único participante afectado con la función de sujeto, en (5b-c) la adición del sufijo -aGat permite la incorporación de un argumento externo agente que instiga la acción. El tipo de causalidad expresada por los verbos derivados mediante -agat es directa e intencional.

(5)

a.

nacheretaegi [: Peroigi]

nache $\quad \varnothing$-Pero-igi

y 3SG.A-arder-LOC

'Estaba prendida'.

b.

¿she?eracatoigeañe cocina?

she-Pera-gat-oige a-ñe cocina

1SG.A-arder-CAU-LOC FEM-D.trid cocina

‘'Prendo la cocina?’

c.

i?eraGatoigi

i-Pera-Gat-oigi

3 SG.A-arder-CAU-LOC

'Lo hace arder'. Buckwalter (1980)

La adición del morfema causativo -agat conlleva un cambio en la morfología de $3^{\text {a }}$ persona singular: por ejemplo, el índice de $3^{\text {a }}$ persona intransitiva $\varnothing$ - de (5a) se convierte en la marca transitiva $i$ - [y-] en (5c). Los ejemplos muestran la operación de aumento de valencia determinada por-agat, que selecciona cláusulas con un único participante afectado $\left(\mathrm{S}_{\mathrm{O}}\right)$. El ejemplo (5a) apoya también lo sugerido por Messineo (2003), que propone que el índice de $3^{\text {a }}$ persona ø- se añade a verbos que seleccionan participantes de baja agentividad o inanimados.

Otro verbo que selecciona el sufijo -agat para formar una construcción causativa es yawik'arder' (6a). Este verbo forma cláusulas intransitivas, a pesar de adjuntarse al índice de persona $i$ - [y-], prototípicamente seleccionado por verbos en cláusulas transitivas. En (6b), el verbo mantiene el índice personal $i$ - [y-], luego de la adjunción del sufijo causativizador-aGat. El ejemplo de (6b) muestra además que el participante A, habilitado por el sufijo causativizador-agat, es expresado inespecíficamente mediante la adjunción de la marca de persona indeterminada qa-.

(6)

a.

yawik na waloq, sowaGat na ntap

y-awik $\quad \varnothing$-na $\quad$ waloq sowagat $\quad \emptyset$-na $\quad$ ntap

3SG.A-arder MASC-D.prox algodón por causa de MASC-D.prox so

'Se quemó el algodón por el sol'. Buckwalter (1980) 
b.

qayawigaGatso?o

qa-y-awig-aGat so?o

IMP-3SG.A-arder-CAU DEM.MASC.dist

'Quemaron eso'.

En el input, -agat ocurre solamente con las raíces de (5) y (6) -awik y -?era, cuyo significado es similar y puede traducirse como 'arder'. Según Censabella $(2006,2008)$, el sufijo causativizador-aGat se adjunta a raíces referidas a estados, como ilustra (5a) —o también dapapita 'está húmedo / empapado' > yapapiagat 'lo moja', aloc 'es alto / largo' > nalogagat 'lo alarga', (Buckwalter 1980)—o eventos espontáneos, como ilustra (6a) —o también dola 'se rompe' > ilagat 'lo rompe', (Buckwalter 1980)—.

\subsection{El sufijo causativizador -aqchet}

Este sufijo se forma a partir del sufijo causativizador -agat —con metátesis, ensordecimiento de la uvular sonora y palatalización de la dental一, más el sufijo -it lexicalizado. Deriva verbos transitivos con significado causativo directo no intencional o involuntario cuando el causante es humano (Censabella 2008). Censabella sostiene que "definir el grado de directividad es problemático, en algunos casos se trata de acciones directas, en otros, indirectas" (Censabella 2006, 11). En el ejemplo (7a-b), se observa que el sufijo añade el significado de causalidad directa.

(7)

a.

abel saishetra?anpotewa?na PanlomaGaqi ten qonshepaGan

abel saishet ra Pan-potew-a? $\emptyset$-na

Abel NEG D.vert 2SG.M-tocar-LOC MASC-D.prox

Pan-lomagaqi ten qo nshepagan

2SG.POS-remera INTERJ después estar.sucio

'Abel no toques la remera porque se va a ensuciar (lit. porque después va a estar sucia)'.

b.

ishipaGanaqchit

i-shipaGan-aqchit

3SG.A-estar.sucio-CAU

'Lo ensucia'. Buckwalter (1980)

El sufijo -aqchet se adjunta a bases intransitivas con un único participante pacientivo, que expresan estados o cambios de estado, y añade un participante agentivo A. Por ejemplo, las bases dalola 'se enferma, está enfermo' o atom 'está frío' son derivadas mediante -aqchet como yalolaqchet 'lo enferma' y yatomaqchet 'lo enfría', respectivamente. Esta última también puede derivarse por medio de la adjunción de -agat como yatomagat 'lo enfría'. La diferencia entre ambas formas se relaciona muy probablemente con la intencionalidad (yatomagat 'lo enfría') o falta de intencionalidad (yatomaqchet 'lo enfría') del participante a cargo del evento causante. En consonancia con su significado causal no intencional (Censabella 2008), el participante A añadido por medio de -aqchet muy frecuentemente es inanimado. En menor medida, -aqchet se adjunta a bases intransitivas que expresan actividades y tienen un único participante agentivo, como deyachi 'anda / viaja mucho, vaga' o desoqo 'gruñe'. 
En el input se hallaron tres ejemplos, prácticamente idénticos, formados sobre la raíz inactiva o estativa -shepagan 'estar sucio' (7c). A diferencia del ejemplo (7b), en el que la adjunción del sufijo causativo determina el cambio al índice de 3a persona transitiva con el prefijo $i-[y-]$, en (7c) el hablante usa el verbo causativizado con el prefijo $n$-, propio del paradigma inactivo o medio. Esto coincide con cierta indeterminación en la traducción: en algunos casos se traduce un significado causativo 'Está ensuciando'; en otros, un significado reflexivo 'Se está ensuciando'. En Buckwalter (1980), la forma reflexiva de este verbo contiene, además del prefijo personal $n$-, el morfema reflexivo -lapt, este último ausente en el ejemplo (7c). Conviene aclarar que la emisión de (7c) fue producida por un niño de 7 años, por lo que la vacilación en la traducción del consultante adulto puede dar cuenta de una equivocación del hablante, propia del proceso de desarrollo de la lengua.

(7)

c.

ten ñenshepaGanaqchet.

ten $\quad \varnothing$-ñe n-shepaGan-aqchet

mirar MASC-D.trid 3SG.M-estar.sucio-CAU

'Mirá, está ensuciando / se está ensuciando.'

\subsection{El sufijo antipasivo -aGan}

Este sufijo se adjunta a bases transitivas y determina la disminución de su valencia, de modo tal que el argumento interno afectado $\mathrm{O}$ es removido. El verbo derivado es intransitivo inergativo, con un único argumento agentivo SA (Censabella 2006, 2008, Carrió 2015 para el mocoví). Si bien Dixon y Aikhenvald (2000) mencionan que algunas construcciones antipasivas admiten la inclusión del argumento O degradado, esto no se observó en ninguno de los ejemplos del toba / qom analizados. Sin embargo, es necesario complementar esta evidencia con elicitaciones sistemáticas para determinar qué tipo de construcciones antipasivas presenta esta lengua.

Según Censabella (2006), su adjunción expresa la idea de que la acción se ha realizado de manera controlada y deseada por un causante, ahora presentado sintácticamente como S. Por ejemplo, luego de la adición del morfema -agan antipasivo en (8a), el evento transitivo en que un participante A 'asa un asado' pierde el participante afectado O da qadawok 'nuestro asado' en (8b). Lo mismo se observa en (9a-b) respecto del evento de 'escribir un papel' que, mediante la adjunción de -agan antipasivo, se transforma en 'escribir', perdiendo el argumento interno $\mathrm{O}$.

(8)

a.

dawogootakañiqadqaya, yawottak da qadawok

d-awo-goo-tak a-ñi qad-qaya

3SG.A-asar-DTR-PROG FEM-D.trid 1PL.POS-hermana

$y$-awot-tak $\quad \varnothing$-da qad-awo-k

3SG.A-asar-PROG MASC-D.vert 1PL.POS-asar-NMZ

'Nuestra hermana está asando nuestro asado'. Buckwalter (1980) 
b. cheta?agerawogootakshegemnte?

$\begin{array}{lll}\text { cheta?age } & \text { r-awo-Goo-tak } & \text { shegemnte? } \\ \text { Recién } & \text { 3SG.A-asar-DTR-PROG } & \text { esta mañana }\end{array}$

'Recién esta mañana está asando'.

(9)

a.

ishetraqayachaigiqaqqayerelek [: qoyerelek] kala papel

i-shet $\quad \emptyset$-ra qa-y-acha-igi qaq

3SG.A-poder MASC-D.vert IMP-3SG.A-poner-LOC y

qo-y-er-elek $\varnothing$-ka la papel

IMP-3SG.A-escribir-DIR MASC-D.aus la papel

'Puede poner adentro y escribir un papel'.

b.

abi(gail) nshetaeqesaqreraGan

abi(gail) n-sheta-eqe saq r-er-aGan

Abi(gail) 3SG.M-querer-DES NEG 3SG.A-escribir-DTR

'Abi(gail) no quiere escribir.'

Es peculiar la convivencia de los afijos -agan causativo y -agan antipasivo, los cuales son idénticos formalmente, pero desempeñan funciones opuestas. Dixon (2000) describe como sumamente infrecuente el que la misma forma tenga una función de aumento y disminución de la valencia. Este autor menciona dos lenguas en las que se observó este fenómeno: el coreano y el songhay —nilo-sahariana, oeste de África-. Resulta más común encontrar un afijo derivativo que codifique dos funciones de aumento o disminución de la valencia (por ejemplo, pasiva y antipasiva).

En el input, -agan antipasivo se adjunta a raíces activas transitivas: -er 'escribir' (9), -?amen 'frotar', -awot 'asar' (8), -?on 'cantar' y -alawat 'matar'; a raíces medias transitivas: -tet 'coser', -qat 'sacar', -qowin 'cazar' y -ata? 'curar'; y también a raíces que participan de ambos paradigmas (-qin 'saludar', -yo 'lavar', -1aqt 'hablar'). Las últimas se comportan ya transitivamente en el paradigma activo e intransitivamente en el medio (iqin 'lo saluda' y nqin 'saluda', yio'lo lava' y nyo 'se lava'), ya transitivamente en ambos (i?agat 'lo cuenta/dice' y n?agatta 'lo declara'). El ejemplo (10a-b) muestra la transformación antipasiva sobre la raíz media transitiva -qowin 'cazar', que deriva un verbo activo. En (11a-c) se presentan ejemplos de -yo 'lavar', raíz que participa tanto de los paradigmas activo como medio. Una vez derivada mediante -agan antipasivo, esta puede adjuntarse a índices de persona del paradigma activo (11b) o medio (11c). Lo mismo sucede con -?aqt 'hablar', pero no con -qin 'saludar', que con -agan antipasivo se adjunta a índices de persona del paradigma activo.

(10)

a.

nqowin

n-qowin

3SG.M-pescar

'Él [lo] pesca'. 
b.

$\begin{array}{lcll}\begin{array}{l}\text { reqoinaGanyoqtakapaapi? } \\ \text { re-qoin- } a_{G} a n\end{array} & \text { yoqta } & \varnothing-k a & \text { paapi } \\ \text { 3SG.A-pescar-DTR } & \text { realmente } & \text { MASC-D.aus } & \text { papi } \\ \text { ‘¿Papá se fue a pescar realmente?’ } & & \end{array}$

(11)

a.

qenaqayimnshipaGan, Penseyogi na yashik

$\begin{array}{lllll}\text { qenaq } & \text { ayim } & \text { nshipaGan } & \text { Pen } & \text { se-yo-gi } \\ \text { cuando } & \text { 1SG.PRON } & \text { estar sucio } & \text { entonces } & \text { 1SG.A-lavar-LOC }\end{array}$

Ø-na $\quad y$-ashik

MASC-D.prox 1SG.POS-cara

'Cuando estoy sucio, entonces lavo mi cara'. Buckwalter (1980)

b.

siyogonqone?

si-yo-Gon qone?

1SG.A-lavar-DTR entonces

'Voy a lavar entonces'.

c.

shikaitñiyogootak

shikait ñi-yo-goo-tak

ayer 1SG.M-lavar-DTR-PROG

'Ayer estuve lavando'.

Como muestran los ejemplos (8-9), el cambio de la clase sintáctica del verbo (de transitivo a intransitivo) conlleva una modificación en el marcador de 3a persona singular del paradigma activo (i- $[y-]$ por $r$ - [d-]). En (10), el índice de persona medio cambia por el activo $(n->r-[d-])$. La raíz -yo 'lavar', compatible con ambos paradigmas en su forma simple, también admite ambos paradigmas una vez derivada mediante -agan antipasivo en (11b-c).

El sufijo -agan se adjunta a bases que expresan eventos durativos no estativos, es decir, actividades o realizaciones como 'escribir' o 'lavar'. Luego de su adjunción y la consiguiente remoción del argumento interno $\mathrm{O}$, el evento expresado pasa a ser atélico.

\subsection{El sufijo causativizador-aganagan}

Este sufijo está compuesto por el morfema antipasivo -agan más el causativizador -aGan, y sirve para expresar causación indirecta intencional (Censabella 2006, 2008). El morfema antipasivo -agan selecciona bases transitivas o transitivizadas y deriva verbos intransitivos (\$3.4), con un único participante $\mathrm{S}_{\mathrm{A}}$. De esta manera, el participante afectado por la acción del sujeto agente es omitido, aunque permanece implícito, dejando libre la posición sintáctica de objeto. Los ejemplos (12a-b) ilustran esta derivación con el verbo 'barrer': en (12a) el verbo es transitivo ('lo barre'), pero se convierte en intransitivo ('barre') luego de la adjunción de -agan antipasivo, tal como evidencia la selección de los índices personales $(i-[y-]>d-[r-])$. A continuación, la adjunción de -agan causativizador incorpora un nuevo participante agentivo, y aquel que anteriormente cumplía la función $\mathrm{S}_{\mathrm{A}}$ pasa a expresar al participante O que lleva a cabo la acción ordenada por A, determinando así la interpretación factitiva ('lo hace barrer') en (12c). 
(12)

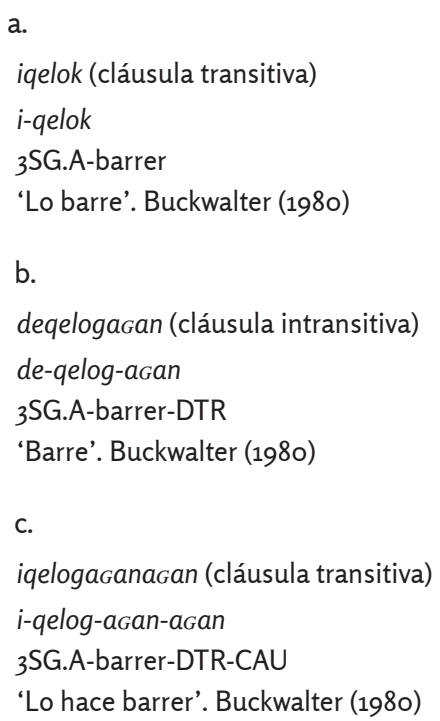

Así como en otras lenguas, como el blackfoot, el halkomelem —Canadá y Estados Unidos-y el bandjalang -Australia-, en toba/qom el verbo transitivo debe detransitivizarse antes de llevarse a cabo la derivación causativa. Es congruente con el hecho de que esta lengua no admite construcciones ditransitivas (ver §1.3). Por lo tanto, para introducir un tercer argumento en la oración (12c), es preciso adjuntar un aplicativo al verbo. (12d) ilustra la incorporación de un tercer argumento por medio del aplicativo -ek. Este argumento, sin embargo, no es nuclear y puede omitirse.

(12)

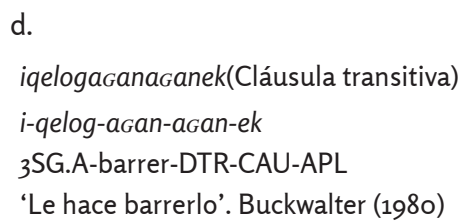

Dos aspectos de las descripciones previas del sufijo -aganagan llaman la atención. En primer lugar, si bien se ha señalado que este sufijo se añade a bases transitivas o transitivizadas, Buckwalter (1980) incluye numerosas ocurrencias con bases intransitivas en su Vocabulario. Por ejemplo, en (13) se observa que las bases para la derivación (izquierda) seleccionan el índice de $3^{\text {a }}$ activa para raíces intransitivas $d$ - $[r$-]. La primera instancia de -agan, que reduce la valencia del verbo 'haciendo lugar' para la inclusión del participante causante, pierde así su motivación con verbos intransitivos con un único participante. Una posible explicación es que el conjunto -aganagan se ha lexicalizado como una unidad impidiendo discriminar los valores de cada uno de los morfemas.

(13)

$$
\begin{array}{ll}
\text { dachot 'gime' } & \rightarrow \text { yachotaGanaGan 'le hace gemir' } \\
\text { dasoknata 'tose' } & \rightarrow \text { yasoknata } \\
\text { dasot 'baila' } & \rightarrow \text { yasota } \\
\text { deloqi 'pelea' } & \rightarrow \text { iloqia }_{G} a a_{G} a n \text { 'le hace han 'le hace bailar' }
\end{array}
$$

En segundo lugar, se ha señalado que las dos instancias de -agan que componen este sufijo pueden ocurrir juntas o separadas (Censabella 2006). 


\begin{tabular}{|c|c|c|c|c|}
\hline Sufijo & $\begin{array}{l}\text { Bases a las que } \\
\text { se adjunta }\end{array}$ & $\begin{array}{l}\text { Cambio en } \\
\text { valencia verbal }\end{array}$ & $\begin{array}{l}\text { Cambio } \\
\text { sintáctico }\end{array}$ & $\begin{array}{l}\text { Cambio } \\
\text { semántico }\end{array}$ \\
\hline $\begin{array}{l}\text { - aGan } \\
\text { causativo }\end{array}$ & $\begin{array}{l}\text { Intransitivas inergativas (SA) } \\
\text { que expresan actividades } \\
\text { y realizaciones. Bases del } \\
\text { paradigma activo y medio. }\end{array}$ & $\begin{array}{l}\text { Incremento. Añade } \\
\text { A. En algunos casos, } \\
\text { añade O (ej. Pash } \\
\text { 'jugar'). }\end{array}$ & $\begin{array}{l}\text { Cláusula intransitiva a transitiva } \\
\text { con cambio en índice de persona } r- \\
{[d-]>i-[y-] \text { para bases del paradigma }} \\
\text { activo. } S A / O>A-O \text {. }\end{array}$ & $\begin{array}{l}\text { Causalidad directa e } \\
\text { indirecta intencional. }\end{array}$ \\
\hline$-a_{G} a t$ & $\begin{array}{l}\text { Intransitivas inacusativas } \\
\text { (SO)que expresan estados, } \\
\text { logros, realizaciones o } \\
\text { actividades. Bases del } \\
\text { paradigma activo. }\end{array}$ & $\begin{array}{l}\text { Incremento. Añade A } \\
\text { (animado). }\end{array}$ & $\begin{array}{l}\text { Cláusula intransitiva a transitiva con } \\
\text { cambio en índice de persona } \emptyset->i- \\
[y-]) . \text { SO }>\text { A-O. }\end{array}$ & $\begin{array}{l}\text { Causalidad directa e } \\
\text { intencional. }\end{array}$ \\
\hline -aqchet & $\begin{array}{l}\text { Intransitivas inacusativas } \\
\text { (SO) que expresan estados } \\
\text { o cambios de estados. } \\
\text { Intransitivas inergativas (SA) } \\
\text { que expresan actividades. }\end{array}$ & $\begin{array}{l}\text { Incremento. Añade } \\
\text { A (inanimado en la } \\
\text { mayoría de los casos). }\end{array}$ & $\begin{array}{l}\text { Cláusula intransitiva a transitiva con } \\
\text { cambio en índice de persona. SO/ } \\
\text { A }>\text { A-O. }\end{array}$ & $\begin{array}{l}\text { Causalidad directa e } \\
\text { indirecta no intencional } \\
\text { o involuntaria. }\end{array}$ \\
\hline$-a_{G} a n a_{G} a n$ & $\begin{array}{l}\text { Transitivas o transitivizadas. } \\
\text { Intransitivas. }\end{array}$ & $\begin{array}{l}\text { Se mantiene para } \\
\text { transitivas (remueve O } \\
\text { y añade A). } \\
\text { Aumenta para } \\
\text { intransitivas (añade A). }\end{array}$ & $\begin{array}{l}\text { Cláusulas transitivas: } \\
\text { Reordenamiento de roles. O es } \\
\text { degradado, su función ocupada por } \\
\text { A original y se añade A. A-O > A-O. } \\
\text { Cláusulas intransitivas: } \\
\text { Transitivización. Participante SA } \\
\text { original ocupa función O y se } \\
\text { incorpora A. SA > A-O }\end{array}$ & $\begin{array}{l}\text { Causación indirecta } \\
\text { intencional. }\end{array}$ \\
\hline - $a_{G} a n a t a_{G} a n$ & $\begin{array}{l}\text { Transitivas o transitivizadas. } \\
\text { Intransitivas. }\end{array}$ & $\begin{array}{l}\text { Disminuye para } \\
\text { transitivas. } \\
\text { Se mantiene para } \\
\text { intransitivas. }\end{array}$ & $\begin{array}{l}\text { Cláusulas transitivas: O es } \\
\text { degradado, su función ocupada } \\
\text { por A original. Se añade A y O (A } \\
\text { original) es degradado. A-O > SA } \\
\text { Cláusulas intransitivas: } \\
\text { SA original ocupa función O y se } \\
\text { incorpora A. Luego O es removido. } \\
\text { SA> SA }\end{array}$ & \\
\hline $\begin{array}{l}\text {-agan } \\
\text { antipasivo }\end{array}$ & $\begin{array}{l}\text { Transitivas que expresan } \\
\text { eventos durativos no } \\
\text { estativos (actividades } \\
\text { o realizaciones). Del } \\
\text { paradigma activo, medio o } \\
\text { de ambos. }\end{array}$ & $\begin{array}{l}\text { Disminución. Remueve } \\
\text { O. }\end{array}$ & $\begin{array}{l}\text { Cláusula transitiva a intransitiva } \\
\text { inergativa (SA) concambio en índice } \\
\text { de persona } i-[y-]>r-[d-], n->r-[d- \\
\text { ]). A-O > SA. }\end{array}$ & $\begin{array}{l}\text { Acción realizada de } \\
\text { manera controlada } \\
\text { y deseada por un } \\
\text { causante. }\end{array}$ \\
\hline
\end{tabular}

Tabla 2. Síntesis de los sufijos estudiados.

\subsection{Frecuencia y productividad de los sufijos estudiados en el input}

En las cuatro horas de transcripción analizadas, se identificaron 42 cláusulas con verbos derivados mediante algunos de los procesos descritos en §3.1§3.5. Estas representan el 3 por ciento del total de enunciados lingüísticos en toba/qom de las transcripciones. Por otra parte, 76 cláusulas contienen ocurrencias no derivadas de las mismas raíces. Es decir, las instancias no derivadas de las raíces recogidas duplican las derivadas.

Quince de las 42 cláusulas con raíces derivadas mediante alguno de los sufijos de cambio de valencia verbal estudiados forman parte del input lingüístico de $\mathrm{Na}$, y representan el 3,2 por ciento del total de enunciados lingüísticos en toba/qom de su input. A su vez, este niño escuchó la mayor cantidad de cláusulas con raíces no derivadas (i.e., 40 cláusulas). En los input de $\mathrm{Ab}$ y $\mathrm{Tg}$, se registraron 11 cláusulas con raíces derivadas, y 10 y 8 cláusulas con raíces no derivadas, respectivamente. Las cláusulas con raíces derivadas mediante los procedimientos de causativización y antipasivización estudiados representan el 3 por ciento y el 3,5 por ciento del total de enunciados lingüísticos en toba/qom del input de A y Tg, respectivamente. Solo se hallaron 5 cláusulas con raíces derivadas en el input 
de Tz, las cuales representan el 1,6 por ciento del total de enunciados lingüísticos en toba / qom que escucha. Además, Tz escuchó 18 cláusulas con raíces verbales no derivadas.

En relación con los distintos sufijos estudiados, se halló un total de 8 ocurrencias del sufijo causativo -agan en las transcripciones correspondientes a dos niños: 6 en el input de Na y 2 en el input de Ab. También se encontraron 3 ocurrencias del sufijo causativo -aqchet, todas en el input de Na. Del sufijo causativo -agat se observaron 10 apariciones en el input de dos niños/as: 6 en el input de Ab y 4 en el input de Tz. El sufijo antipasivo -agan se registró un total de 20 veces y es el único que aparece en todas las transcripciones analizadas: 11 veces en el input de Tg, 5 en el input de $\mathrm{Na}, 3$ en el input de Ab y 1 en el input de Tz. Por último, sólo se registró 1 ocurrencia del sufijo causativo -aganagan en el input de $\mathrm{Na}$.

Por otra parte, sólo 2 cláusulas que contienen alguno de los sufijos analizados fueron dirigidas a un niño, ambas a Na: una de ellas con -agan causativo y la otra con -agan antipasivo. El resto de las emisiones con sufijos de cambio de la valencia verbal (i.e., 40 emisiones) fueron dirigidas a adultos/as. Esto se observa en la Figura 1, donde el habla dirigida a niños/as — gráficos superior e inferior izquierdos- está compuesta casi exclusivamente de cláusulas sin los sufijos estudiados - barras color amarillo-. Respecto de los/as hablantes, -agan causativo fue encontrado en 6 cláusulas producidas por niños/as y tan solo 2 producidas por adultos/as. En el caso de -aGat, 4 cláusulas producidas por adultos/as y 6 producidas por niños/as contienen el sufijo. Respecto de -agan antipasivo, fueron 16 las cláusulas producidas por adultos/as y 4 las cláusulas producidas por niños/as que contienen el sufijo. Por último, todas las instancias de aparición de -aqchet (3) y la única aparición de -aganagan fueron producidas por un/a niño/a. La información acerca de la frecuencia de los sufijos estudiados se puede visualizar en la figura 1.

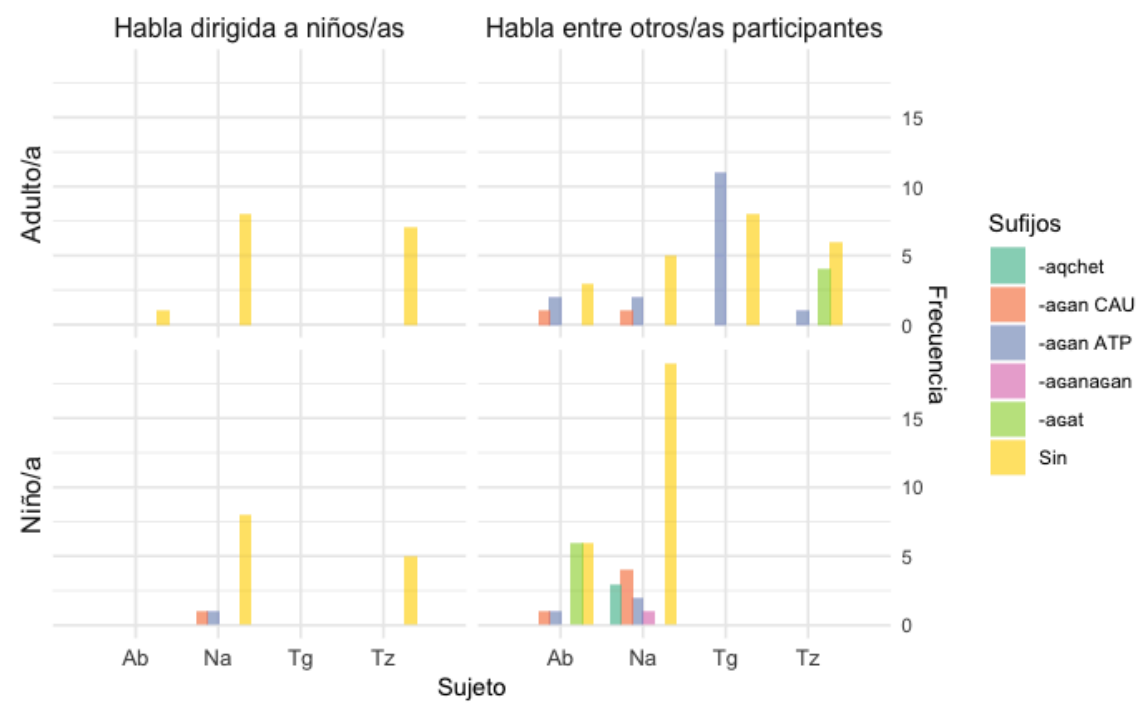

Figura 1. Frecuencia de los sufijos de cambio de la valencia verbal en el input según sujeto, hablante y destinatario.

En relación con la diversidad de raíces a las que se añaden, -aGan causativo ocurrió con 5 raíces distintas en total, -aqchet solo con 1 raíz, -agat con 2 raíces distintas, -agan antipasivo con 12 raíces distintas y -aganagan con 1 
raíz. A continuación, se observó si la misma raíz se encontraba disponible en el input con y sin los sufijos de cambio de la valencia verbal estudiados. Como puede observarse en la figura 2, esto solo se verifica para las raíces -an'dar', -shepagan 'ensuciar', -malla 'hablar', ?amen'frotar', ?aqt'hablar' y ?ash 'jugar' en el input de Na; -qat 'sacar' y -yo 'lavar' en el input de Tg; y -yo 'lavar' y ?er 'arder' en el input de Tz. En cambio, en el input de Ab, la misma raíz nunca ocurre a la vez derivada y no derivada mediante alguno de los procesos analizados.

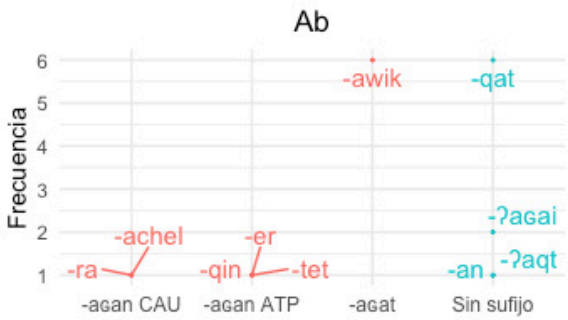

$\mathrm{Tg}$

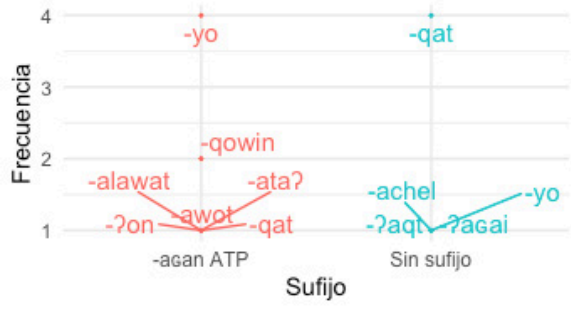

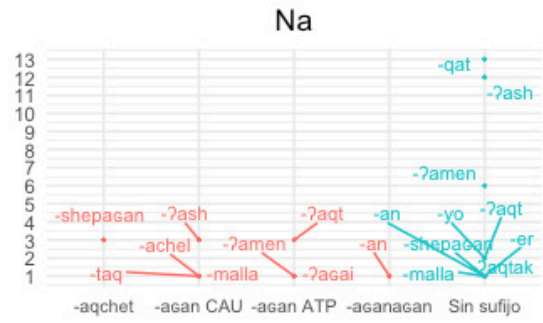

$\mathrm{Tz}$

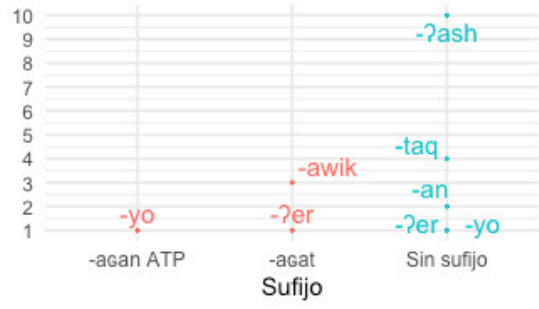

Figura 2. Frecuencia de las raíces por sujeto según ocurran con y/o sin sufijos de cambio de la valencia verbal.

\section{Conclusión}

En este trabajo se han analizado un conjunto de estrategias morfológicas de aumento o reducción de la valencia verbal en toba/qom, contribuyendo así con descripciones previas. Se proporcionaron ejemplos de un corpus de habla espontánea siempre que los hubiese. Asimismo, se estudió la información morfológica presente en el input toba/qom para reflexionar acerca de los mecanismos que intervienen en la adquisición de los verbos, los cuales no son puestos a prueba aquí directamente. Para nuestro análisis, la estrategia de mayor interés es la conocida bajo el nombre de bootstrapping sintáctico, que sostiene que el aprendizaje de la semántica verbal es guiado por la información que la estructura gramatical de una lengua proporciona al/a niño/a. Según las características tipológicas de la lengua en cuestión, esta información puede ser preeminentemente sintáctica o morfológica.

El análisis de las operaciones de aumento o disminución de la valencia verbal sugiere que son indicios valiosos para el/la niño/a que debe aprender el significado verbal en toba/qom. En primer lugar, resultan más consistentes que los procedimientos sintácticos, como la cantidad de argumentos o el orden de constituyentes. Estos conducen a error en la interpretación del verbo -achel 'bañar' de (1a)-(1b), entre otros casos. La menor consistencia de los dispositivos sintácticos en la expresión de la transitividad verbal se relaciona con la posibilidad del toba/qom de omitir argumentos y la ausencia de órdenes contrastivos de aplicación general que diferencien las cláusulas transitivas de las intransitivas. 
En segundo lugar, las operaciones morfológicas descritas son interpretadas localmente, lo cual constituye una ventaja por sobre las operaciones sintácticas, que se encuentran distribuidas en la oración y deben ser integradas por el/la niño/a para su procesamiento. A pesar de esto, algunos estudios mencionados han observado que niños/as que se encuentran aprendiendo lenguas morfológicamente ricas atienden a procedimientos sintácticos para interpretar el significado verbal. Al respecto, es de gran relevancia el estudio de Lidz et al. (2003) que investiga niños/as que aprenden kannada, una lengua que, además de marcas de caso, dispone de un sufijo que señala si el verbo expresa un significado causativo. Si bien el toba/qom no dispone de marcas de caso (§1.3), cuenta con distintos sufijos que, como en kannada, indican que el significado del verbo es causativo, e incluso discrimina distintos tipos de causatividad, ya directa como -agat o -aqchet, ya indirecta como -aganagan.

Estudios experimentales como el de Lidz et al. (2003) deben ser complementados con un análisis del input espontáneo al que se encuentra expuesto/a el/la niño/a. Determinar la frecuencia de aparición de los dispositivos morfológicos de aumento y disminución de la valencia verbal puede evitar sacar conclusiones apresuradas acerca de los mecanismos que los/as niños/as utilizan para interpretar los verbos. A pesar de que una lengua disponga de dispositivos morfológicos para señalar la valencia verbal, cabe la posibilidad de que estos no ocurran frecuentemente en el input. En esos casos, los resultados de estudios experimentales estarían informando no tanto acerca de disposiciones universales para el aprendizaje de los verbos, sino más bien acerca de la información que se encuentra disponible en el input espontáneo de cada lengua.

En este sentido, los estudios de Rispoli (1995) con niños/as japoneses/as de 2 años sostienen que la marcación de caso en japonés es demasiado infrecuente para ser utilizada en la interpretación del significado de verbos nuevos. Por su parte, el presente trabajo mostró que, a pesar de que la morfología de cambio de la valencia verbal es un apartado destacado en las descripciones tipológicas del toba/qom, su frecuencia en el input es baja (menos del 5\%). No obstante, es preciso aclarar que el presente análisis no fue exhaustivo, dado que quedaron fuera algunos sufijos que también brindan información acerca de la estructura argumental del verbo (por ejemplo, los sufijos aplicativos o los prefijos personales de 3a persona activa).

Por otro lado, llama la atención que en general no se les dirija cláusulas con sufijos de cambio de la valencia verbal a los/as niños/as. Esto no es menor, teniendo en cuenta el efecto predictivo que caracteriza al habla dirigida al/a niño/a acerca del desarrollo lingüístico (Weisleder y Fernald 2013, entre otros). Solo dos ocurrencias de los sufijos estudiados fueron dirigidas a niños/as: una de -agan causativo y una de -agan antipasivo. Esto puede relacionarse con el carácter más simplificado de este registro (Soderstrom 2007). A su vez, ambas ocurrencias fueron dirigidas al mismo niño (Na), el de mayor edad dentro de la muestra. De allí que la simplicidad morfológica observada en el input de los/as otros/as niños/as puede relacionarse con su desarrollo lingüístico y los efectos que esto conlleva en su interlocutor. A pesar de que no se les dirigen cláusulas con sufijos de cambio de la valencia verbal, otros/as niños/as del entorno han aprendido estas formas y las emplean regularmente. En efecto, observamos que la mitad de las instancias documentadas en el corpus estudiado fueron producidas por niños/as menores de 12 años $^{8}$.
8. Veinte de las 42 cláusulas del input que contienen verbos derivados mediante algunos de los procesos estudiados fueron producidas por otros niños del entorno (ver \$3.7). 
El presente análisis también reveló que entre los morfemas estudiados los más frecuentes son: -agan antipasivo, que ocurre el doble de veces respecto del segundo sufijo más frecuente, y en todos los/as niños/as del corpus analizado; y el sufijo -agat de aumento de la valencia verbal. No obstante, si bien -agan antipasivo es el único sufijo que se registró en el input de todos/ as los/as niños/as, en uno de ellos/as (Tg) su frecuencia es muy superior. El sufijo menos frecuente en el corpus analizado es -aganagan, que permite derivar verbos transitivos que expresan causalidad indirecta intencional. Además, el único ejemplo del input con este sufijo se encuentra, en gran parte, lexicalizado.

El análisis de la diversidad de raíces con las que ocurren los sufijos analizados mostró que -agan antipasivo ocurre con la mayor diversidad de raíces. Asimismo, si bien -agan causativo y -agat ocurren con frecuencia similar, -agan causativo se adjunta a una cantidad mayor de raíces distintas. El análisis por niño/a permitió determinar si en el curso de una hora el/la niño/a oye la misma raíz a la vez derivada y no derivada mediante alguno de los sufijos estudiados, lo cual constituye una oportunidad propicia para identificar los componentes del verbo y su contribución al conjunto. Al respecto, 3 de los/as 4 niños/as oyen instancias derivadas y no derivadas de las raíces durante 1 hora.

Como conclusión, si bien las operaciones morfológicas del toba/qom suministran información valiosa y potencialmente más consistente que aquella proporcionada por la sintaxis, el análisis de su frecuencia en el input mostró que su disponibilidad es sumamente baja — sobre todo en el habla dirigida a niños/as-. De este modo, no parece razonable postular que la presencia de morfología de aumento y disminución de la valencia verbal sea el factor principal en el aprendizaje del significado de los verbos en toba/qom. Sin embargo, los resultados de nuestro análisis permiten cuestionar la premisa sostenida por los defensores del bootstrapping sintáctico de que la atención a la información sintáctica responde a disposiciones universales para el aprendizaje de los verbos. La preferencia por la información sintáctica, observada en niños/as que aprenden algunas lenguas con recursos morfológicos para señalar la estructura de argumentos del verbo, puede indicar simplemente que tales recursos escasean en el input espontáneo de aquellas lenguas.

En el futuro, incluiremos otros sufijos que informan acerca del significado causativo del verbo, a fin de determinar si estos resultados se mantienen. Además, evaluaremos la disponibilidad y consistencia de información sintáctica, por ejemplo, la cantidad de argumentos expresados independientemente y el orden de constituyentes. 


\section{Q Bibliografía}

"Ammon, Mary S. y Dan I. Slobin. 1979. "A cross-linguistic study of the processing of causative sentences". Cognition 7.1: 3-17.

" Audisio, Cynthia, Celia Rosemberg, Gladys Ojea y Paola Cúneo 2019. “Bilingual input to children from a Qom community in Chaco (Argentina)". Trabajo presentado en el Fifth Intergenerational Transmission of Minority Languages Symposium: Language, Culture and Ethnicity in Indigenous and Migrant Languages (ITMLs), Stockholm University (Suecia) y University of Canterbury (Nueva Zelanda). https://www.isd.su.se/english/itml// presentations/bilingual-input-to-children-from-a-qom-community-in-chaco-argentina-1.466249

» Buckwalter, Alberto S. 2001 [1980]. Vocabulario toba. Formosa, Indiana: Equipo Menonita.

" Carpio, María Belén. 2007. "Sistemas de alineación en toba (familia guaycurú, Argentina)". Tesis de Maestría, Universidad de Sonora.

" Carrió, Cintia. 2015. "Construcciones causativas y anticausativas en Mocoví". LIAMES: Línguas Indígenas Americanas 15.1: 69-89. doi:10.20396/liames.v15i1.8641496.

"Censabella, Marisa. 1998. “Axiología de la voz media en toba”. En Actas III Jornadas de Lingüística Aborigen, 91-101. Buenos Aires: Instituto de Lingüística, Universidad de Buenos Aires.

"Censabella, Marisa. 2000. Las lenguas indígenas de la Argentina: Una mirada actual. Buenos Aires: Eudeba.

"Censabella, Marisa. 2006. "Causación directa, sociativa e indirecta en toba". En Actas del Encuentro de Lenguas Indígenas Americanas, 15-17 de junio de 2006. Santa Rosa: Universidad Nacional de La Pampa. CD-Rom.

"Censabella, Marisa. 2008. “Derivación causativa en lengua toba”. En Studies in voice and transitivity, editado por Zarina Estrada Fernández, Søren Wichman, Claudine Chamoreau y Albert Álvarez González, 105-125. Múnich: Lincom Europa.

" Choi, Soonja. 1999. "Early development of verb structures and caregiver input in Korean: Two case studies". The International Journal of Bilingualism 3: 241-265.

"Comrie, Bernard. 1976. "The syntax of causative constructions: Cross-language similarities and divergences”. En The grammar of causative constructions, editado por Masayoshi Shibatani, 261-312. New York: Academic Press.

"Comrie, Bernard. 1981. Language universals and linguistic typology: Syntax and morphology. Oxford: Basil Blackwell.

»Cúneo, Paola y Cristina Messineo. 2019. “Orden de palabras, posición del objeto y estructura de la información en toba/qom (Guaycurú)". En Estudios de interfaz sintaxis-pragmática en español y lenguas de América, editado por Valeria A. Belloro, 41-66. Berlín, Boston: De Gruyter Mouton. https://www.degruyter.com/downloadpdf/book s/9783110605679/9783110605679-003/9783110605679-003.pdf

》 DGEEC. 2015. III Censo Nacional de Población y Viviendas para Pueblos Indígenas: Resultados finales 2012. Asunción: Dirección General de Estadísticas, Encuestas y Censos.

》Dixon, Robert M.W. 1994. Ergativity. Cambridge Studies In Linguistics 69. Cambridge: Cambridge University Press. 
» Dixon, Robert M.W. 200o. “A typology of causatives: Form, syntax and meaning”. En Changing Valency. Case Studies in transitivity, editado por Robert M.W. Dixon y Alexandra Aikhenvald, 30-83. Cambridge: Cambridge University Press.

» Dixon, Robert M.W. y Alexandra Aikhenvald. 2000. “Introduction”. En Changing Valency. Case Studies in transitivity, editado por Robert M.W. Dixon y Alexandra Aikhenvald, 1-29. Cambridge: Cambridge University Press.

» Fisher, Cynthia. 1996. "Structural limits on verb mapping: The role of analogy in children's interpretations of sentences". Cognitive Psychology 31: 41-81.

» Fukuda, Shin y Choi, Soonja. 2009. "The acquisition of transitivity in Japanese and Korean children”. Japanese and Korean Linguistics 17: 613-624.

» Gentner, Dedre. 1978. “On relational meaning: The acquisition of verb meaning”. Child development 988-998.

» Gleitman, Lila. 1990. “The structural sources of verb meanings”. Language acquisition 1.1: 3-55.

» Goksun, Tilbe, Aylin C. Küntay y Letitia R. Naigles. 2008. “Turkish children use morphosyntactic bootstrapping in interpreting verb meaning". Journal of Child Language 35: 291-323.

» González, Raúl E. y María Belén Carpio. 2017. "Causativización perifrástica en toba del este y del oeste de la provincia de Formosa (Argentina)”. Íkala, Revista de Lenguaje y Cultura 22.3: 439-454. doi:10.17533/udea.ikala.v22no3ao5.

» Gumperz, John. 1982. Discourse Strategies. Cambridge: Cambridge University Press.

» Hoff-Ginsberg, Erika. 1986. "Function and structure in maternal speech: Their relation to the child's developmental of syntax". Developmental Psychology 22, no. 2, 155-163.

» INDEC. 2004. Encuesta Complementaria de Pueblos Indígenas. Buenos Aires: Instituto Nacional de Estadística y Censos.

» INDEC. 2012. Censo Nacional de Población, Hogares y Viviendas 2010. Resultados definitivos. Buenos Aires: Instituto Nacional de Estadística y Censos.

» Ingham, Richard. 1993. "Critical influences on the acquisition of verb transitivity". En Critical influences on child language acquisition and development, editado por David J. Messer y Geoffrey J. Turner, 121-137. London: Palgrave Macmillan.

» Klein, Harriet E. M. 1981. Una gramática de la lengua toba: morfología verbal y nominal. Montevideo: Universidad de la República.

" Lee, Joanne N. y Letitia R. Naigles. 2008. "Mandarin learners use syntactic bootstrapping in verb acquisition.” Cognition 106, no. 2: 1028-1037.

» Lidz, Jeffrey, Henry Gleitman y Lila Gleitman. 2003. “Understanding how input matters: verb learning and the footprint of universal grammar". Cognition 87, no. 3: 151-78.

» MacWhinney, Brian. 1987. “The competition model”. En Mechanisms oflanguage acquisition, editado por Brian MacWhinney, 249-308. Hillsdale, NJ: Lawrence Erlbaum.

» MacWhinney, Brian. 200o. The CHILDES Project: Tools for analyzing talk (3ra edic.). Mahwah, NJ: Erlbaum.

» Matsuo, Ayumi, Sotaro Kita, Yuri Shinya, Gary C. Wood y Letitia Naigles. 2012. “Japanese two-year-olds use morphosyntax to learn novel verb meanings". Journal of Child Language 39: 637-663.

» Messineo, Cristina. 2003. Lengua toba (guaycurú). Aspectos gramaticales y discursivos. Lincom Studies in Native American Linguistics, 48. Lincom Europa Academic Publisher. 
» Messineo, Cristina. 2016. “Indexación y orden: huellas de alineamiento jerárquico en toba (Guaycurú)”. Trabajo presentado en el XV Congreso de la Sociedad Argentina de Lingüística, Bahía Blanca, Argentina, 11-14 de mayo.

» Morikawa, Hiromi. 1989. “Acquisition of case marking and predicate-argument structures in Japanese: A longitudinal study of language acquisition mechanisms”. Tesis de doctorado, University of Kansas.

» Ninio, Anat. 2015. "The first vocabulary of transitive verbs in Hebrew is apparently learned from single-word parental utterances”. Trabajo presentado en el Biennial Meeting of the Society for Research in Child Development, Philadelphia, Pennsylvania, USA.

» Ninio, Anat. 2016. "Learning transitive verbs from single-word verbs in the input by young children acquiring English.” Journal of Child Language 43.5: 1103-1130.

» Ojea, Gladys. 2017. “Bilingüismo y alfabetización: Un estudio sobre el aprendizaje del sistema de escritura en niños qom bilingües qom-español”. Tesis de doctorado. Buenos Aires: Facultad de Filosofía y Letras, UBA.

» Pinker, Steven. 1984. Language learnability and language development. Cambridge, MA: Harvard University Press.

» Rispoli, Matthew. 1995. "Missing arguments and the acquisition of predicate meanings". En Beyond names for things: Young children's acquisition of verbs, editado por Michael Tomasello y William E. Merriman, 331-352. Hillsdale, NJ: Lawrence Erlbaum.

» Rosemberg, Celia, Florencia Alam, Alejandra Stein, Maia Migdalek, Alejandra Menti y Gladys Ojea. 2015-2016. El entorno lingüístico de niños pequeños argentinos/Language environments of young argentinean children. CONICET (DOI en proceso).

»Shibatani, Masayoshi y Prashant Pardeshi. 2002. "The causative continuum". En The grammar of causation and interpersonal manipulation, editado por Masayoshi Shibatani, 85-126. Ámsterdam, Filadelfia: John Benjamins.

» Slobin, Dan. 1982. “Universal and particular in the acquisition of language”. En Language acquisition: The state of the art, editado por Lila Gleitman y Eric Wanner, 128-172. Cambridge: Cambridge University Press.

»Soderstrom, Melanie. 2007. "Beyond babytalk: Reevaluating the nature and content of speech input to preverbal infants”. Developmental Review 27, no. 4, 501-532.

» Song, Jae Jung. 2001. Linguistic typology: Morphology and syntax. Harlow: Pearson.

»Suzuki, Takaaki y Tessei Kobayashi. 2016. "Syntactic cues for inferences about causality in language acquisition: Evidence from an argument-drop language”. Language Learning and Development 13.1: 24-37.

» Tsujimura, Natsuko. 2006. "Why not all verbs are learned equally: The intransitive bias in Japanese". En The Acquisition of verbs and their grammar: The effect of particular languages, editado por Natalia Gagarina y Insa Guilzow, 105-122. Dordrecht: Springer.

»Weisleder, Adriana y Anne Fernald. 2013. "Talking to children matters: Early language experience strengthens processing and builds vocabulary". Psychological science 24.11: 2143-2152.

"Yuan, Sylvia, Cynthia Fisher y Jesse Snedeker. 2012. “Counting the nouns: Simple structural cues to verb meaning”. Child Development 83.4: 1382-1399.

»Zurlo, Adriana A. 2016. “Voz media en toba (guaycurú)”. LIAMES: Línguas Indígenas Americanas 16.2: 285. doi:10.20396/liames.v16i2.8646309. 